\author{
ANNUAL MEETING \\ KING EDWARD HOTEL, TORONTO
}

Symposium - Sunday June 15, 1969

An all-day symposium of lectures by a faculty of members and invited guests will be held on the day prior to the Annual Meeting.

Subject: "Respiratory Care"

Registration: $\$ 30.00$. (Residents in anaesthesia free, up to capacity, on presentation of a letter from the head of their department.) Prior registration, which should be accompanied by a cheque, may be made by writing to: The Secretary, Canadian Anaesthetists' Society, 178 St. George Street, Toronto 5.

Scientific Programme - June 16-19

The scientific programme will consist of original papers, the Residents' Competition, and panels on "Organ Transplantation and the Anaesthesiologist" and "Perinatal Resuscitation."

The Wellcome Lecture will be given by Dr. Martin Holmdahl.

Applications to present papers should be sent before January 17, 1969, to: The Chairman, Scientific Programme Committee, Canadian Anaesthetists' Society, 178 St. George Street, Toronto 5. 


\section{ANNUAL MEETING: RESIDENTS’ COMPETITION}

\section{RULES OF COMPETITION}

1. The objective of the competition shall be to encourage scientific excellence in physicians training in the specialty of anaesthesia in Canada.

2. Candidates must be members or members-elect of the Canadian Anaesthetists' Society at the time of the competition, and occupying the position of Resident, Fellow, or Research Fellow in a Canadian department of anaesthesia. Those completing work beyond the first year of a Master's or Doctoral programme of a Graduate School will be ineligible.

3. The work presented must have been carried out in Canada and completed in the preceding 18 months, prior to obtaining the specialist certificate of the Royal College of Physicians and Surgeons of Canada or of the College of Physicians and Surgeons of Quebec.

4. The Scientific Programme Committee will be responsible for the details of the conduct of the competition and will select the best submissions from those entered, for presentation at the Annual Meeting.

5. The Chairmen of Canadian university departments of anaesthesia (or, in their absence, a previously nominated deputy) will act as judges, scoring each candidate according to a previously agreed system. Three prizes $(\$ 500, \$ 300, \$ 200)$ will be awarded, at the discretion of the judges, to the best of the eight papers presented at the meeting. The eight papers to be presented will be selected previously by the Scientific Programme Committee, from abstracts (less than 500 words) submitted before March 7, 1969.

6. Entries for the competition should be in the form of abstracts and should be submitted, prior to March 7, 1969, to the Chairman, Scientific Programme Committee, Canadian Anaesthetists' Society, 178 St. George Street, Toronto 5. 